\title{
STRESS-STRAIN RESPONSE MODELLING OF GLASS FIBRE REINFORCED EPOXY COMPOSITE PIPES UNDER MULTIAXIAL LOADINGS
}

\author{
M.S. Abdul Majid ${ }^{1 *}$, R. Daud ${ }^{1}$, M. Afendi ${ }^{1}$, N.A.M Amin ${ }^{1}$, E.M. Cheng ${ }^{1}$, \\ A.G. Gibson ${ }^{2}$ and M. Hekman ${ }^{3}$ \\ ${ }^{1}$ School of Mechatronic Engineering, Universiti Malaysia Perlis (UniMAP), \\ Pauh Putra Campus, 02600, Pauh, Perlis, Malaysia \\ Phone: +612-7367500; Fax: +604-988 5167 \\ *Email: shukry@unimap.edu.my \\ ${ }^{2}$ Newcastle University, Stephenson Building, Newcastle upon Tyne, NE1 7RU, UK \\ ${ }^{3}$ Technology \& Engineering Developments Future Pipe Industries (FPI), UAE
}

\begin{abstract}
This paper presents the modelling of the stress strain response of glass fiber reinforced epoxy (GRE) composite pipes subjected to multiaxial loadings at room temperature (RT). This particular modeling work was developed to predict the non-linear stress strain response caused by the fatigue cyclic and static loading in the multiaxial ultimate elastic wall stress (UEWS) tests by considering the effects of matrix cracking within the laminates. The UEWS test, whilst not yet standardized, appears to offer an attractive alternative to existing procedures of qualifying GRE pipes. The ply properties initially expressed as a function of crack density were computed as a function of increasing stress and strain using shear lag approximation. The results show that the model developed from the classical laminate theory which takes into account whether the effects of transverse matrix micro-cracks on stiffness and strains is capable of predicting the resulted elastic properties. The predictions are found to be in good agreement with the data from multiaxial UEWS tests on $\pm 55^{\circ}$ filament wound glass-reinforced epoxy pipes.
\end{abstract}

Keywords: Stress strain response; multiaxial loadings; composite pipes; cyclic and static loading; crack density.

\section{INTRODUCTION}

The failure behavior of filament wound GRE pipes subjected to biaxial load has been the subject of numerous experimental and modelling investigations spanning decades, as demonstrated in the literature (Bachtiar, Sapuan, \& Hamdan, 2010; Carvalho \& Marques, 2007; Frost \& Cervenka, 1994; Gibson, Saied, Evans, \& Hale, 2003a, 2003b; Hale, Shaw, Speake, \& Gibson, 2000; Hull, Legg, \& Spencer, 1978; Jeffrey, Tarlochan, \& Rahman, 2011; Meijer \& Ellyin, 2008; Mertiny \& Ellyin, 2006; Ravi Sankar, Srikant, Vamsi Krishna, Bhujanga Rao, \& Bangaru Babu, 2013; Salleh, Yusop, \& Rosdi, 2013; Tarakcioglu, Gemi, \& Yapici, 2005). The majority of such investigations have emphasized failure envelopes, fatigue strength, leakage and the associated deformation of angle ply laminates similar to those used in GRE pipes. However, whilst most of these studies concentrated on structural failure in composite pipes, the more significant issue of micro structural progressive damage, which leads to the final failure, is less clear. Most of the literature has reported that filament wound composite pipes under fatigue biaxial load failed due to sequences of damage which 
involved transverse matrix cracking, delamination, weepage and fiberfracture (Jones \& Hull, 1979). This is illustrated in Figure 1 (Reifsnider, Henneke, Stinchcomb, \& Duke, 1983). Increases in applied load cause the continuous nucleation and accumulation of transverse matrix cracks along the fiber direction. When the matrix crack density reaches saturation, delamination, weepage and fiber fracture may occur thus causing a rapid progression of damage leading to final catastrophic failure.

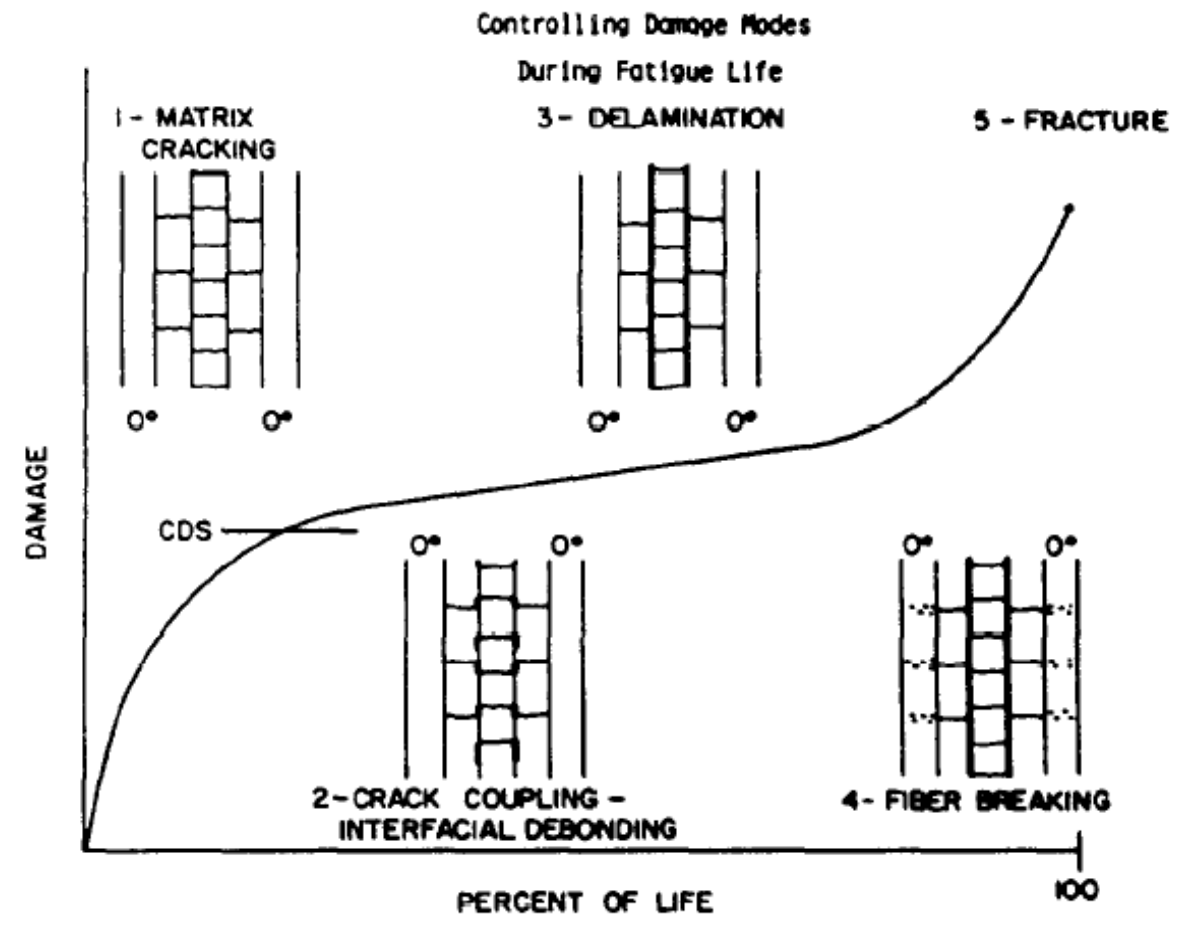

Figure1. Sequence of damage development in composite laminates during fatigue loading (Reifsnider et al., 1983).

Matrix cracking within composite laminates has been recognized as the major factor causing reduction in the stiffness of laminates. Various models have been presented to characterize such degradation in stiffness as due to transverse matrix cracking under in-plane uniaxial and multiaxial loading (Kamal, Rahman, \& Rahman, 2012; Kamal, Rahman, \& Sani, 2013; Rahman, Ariffin, Rejab, Kadirgama, \& Noor, 2009). Among these models are the ply-discount approximation (Hanh \& Tsai, 1974), the continuum damage model (Li, Reid, \& Soden, 1998; Nairn \& Hu, 1994), shear lag model (Highsmith \& Reifsnider, 1982; Norman \& Dvorak, 1988), self-consistent scheme (Laws, Dvorak, \& Hejazi, 1983), and the variational model proposed by Hashin (1985) and Praveen \& Reddy (1998). Recently, Katerelos, McCartney, \& Galiotis (2006) conducted an analysis of the effect of matrix cracking on the behavior of angle ply laminates loaded statically using the equivalent constraint model (ECM). The approach showed good agreement with the experimental results obtained by microscopic strain measurement using the laser Roman spectroscopy technique Katerelos, Lundmark, Varna, \& Galiotis (2007).

A finite element model was proposed by Tao and Sun (1996) and Sun and Tao (1998), who investigated the effects of matrix cracking on the stiffness degradation of laminates. The predicted normalized transverse and shear modulus was later plotted 
against the exponential function of the normalized crack density of a cracked lamina. The authors concluded that normalized crack density rather than crack density was a more appropriate parameter for use in predicting cracking damage. Frost and Cervenka (1994) studied the influence of loading frequency in predicting the long term fatigue behavior of a GRE pipe. They concluded that the prime failure mechanism observed for short and long term fatigue was leakage as a result of matrix cracking. As mentioned earlier, although transverse matrix cracking may not cause abrupt structural damage in pipeline applications, it is highly detrimental since it leads to weepage failure which, if not treated, can trigger the development of other, more deleterious forms of damage such as fiber breakage or bursting. Recently Gibson \& Abdul Majid (2011) have shown that a Miner's law approach is effective in modelling damage due to combined static and cyclic effects, and that damage can be directly related to matrix crack growth. This approach could form the basis of a future procedure for describing the lifetime behavior of glass reinforced epoxy pipes under any required combination of static, fatigue, hydrostatic and non-hydrostatic (multiaxial) loading. This present investigation models the stress strain response of GRE pipes as the result of transverse matrix cracking during multiaxial UEWS tests. The results were compared with the experimental UEWS data to achieve the closest fit.

\section{ULTIMATE ELASTIC WALL STRESS}

While the current procedure for qualifying GRE pipes based on regression analysis provides very good predictions of the long term behavior of the pipes, manufacturers are driven by the need for a faster and simpler qualification process. A number of possible short term tests have been examined such as the inter laminar shear stress (ILSS), flexural and UEWS tests. The UEWS test is not yet standardized, but appears to offer an attractive alternative to existing procedures. Its principles were first investigated by Shell Research in 1968 (Schwencke, 1968). Limited studies have reported on this procedure. Hull et al. (1978) and Frost \& Cervenka (1994) both reported on the UEWS test and observed that matrix cracking is consistently associated with non-linearity in stress strain responses. The intention of the UEWS test is to identify, by examining the stress-strain response, a stress level below which damage growth is either negligible or at least sufficiently low to prevent long term failure in the design life. GRE pipe fails when debonding occurs between the fibers and matrix interface. Once debonding takes place, there will be less surface area for proper stress distribution. This leads to the development of stress concentrations within the GRE system which, in turn, cause further debonding. The point at which the fiber-matrix interface starts to debond is used as an indication of the borderline between permissible and non-permissible deformation. This point is called the ultimate elastic wall stress (UEWS).

The UEWS test involves the application of groups of 10 one-minute hydrostatic pressure cycles at increasing pressure levels. The strain at the end of the first and the last cycle of each ten cycle group is measured, and these values are plotted against pressure (or hoop stress). If zero or negligible damage occurs at a particular pressure level, then a linear relationship is recognized between strain and hoop stress, and the strain after the tenth cycle in the group is the same as at the first cycle. As the UEWS is approached, a deviation in strain can be seen between the first and the last cycle, and the relationship begins to become non-linear. This non-linearity in the stress-strain relationship will then be used to indicate the UEWS point which corresponds to first ply 
failure in the pipe. Further details ofthe UEWS test procedure and the calculations involved were given in recent paper by Abdul Majid et al. (2011).

\section{THE MODEL}

Preceding the UEWS testing, the theoretical mechanical properties of the individual ply and the laminates or the pipe were calculated and later compared with the experimental results. In this approach, micromechanics theory was used to derive the elastic properties of the unidirectional ply from those constituent composites using Hill and Halpin-Tsai simplification analysis formulation. First, for the calculation of reinforcement fiber, the rule of mixtures was used to predict the $E_{1}$ and $v_{12}$ to a good accuracy. However, the same treatment of predicting $E_{2}$ gives a large error due to the non-uniform distribution of stress and strain in transverse direction. Hence, the HalpinTsai simplification was used instead to calculate the $E_{2}$ and $G_{12}$ of the ply. Based on isotropic glass fiber reinforcement properties provided by FPI for the Wavi strong pipe product; $E_{g}=73 \mathrm{GPa}$ and $v_{\mathrm{g}}=0.59$, epoxy matrix properties; $E_{m}=3.6 \mathrm{GPa}$ and $v_{\mathrm{m}}=$ 0.41 , the ply properties were calculated to be $E_{1}=44.5 \mathrm{GPa}, E_{2}=12.2 \mathrm{GPa}, G_{12}=4.33$ and $v_{12}=0.28$. The properties of the $\pm 55^{\circ} \mathrm{GRE}$ pipe were then computed using laminate theory and given in the axial and hoop direction of the pipe. The details oflaminate theory will not be discussed here but is derived in details in most composite laminate resources. From the calculation,

$$
\begin{array}{lll}
E_{\text {axial }}=11.52 \mathrm{GPa} & E_{\text {hoop }}=19.70 \mathrm{GPa} \\
v_{\text {axial }}=0.40 & v_{\text {hoop }}=0.69 \\
G_{12}=11.76 \mathrm{GPa} &
\end{array}
$$

It is also important to note that the radial component in this case is much lower than that of the axial and hoop components and therefore, ignored.

\section{Stress-Strain Modeling}

In this section, the overall stress strain curves of the UEWS test at various stress ratios were modeled by implementing 'superposition' of linear and non-linear responses, predicted separately. Under increasing group cycle pressure, the axial and hoop strains computed from elastic analysis were simply superposed together with the strains caused by the stiffness degradation due to transverse matrix cracking.

For internal pressure loading of only filament wound GRE pipes, the stress is calculated from the following equation;

$$
\begin{gathered}
\sigma_{H}=\frac{P d}{2 t} \\
\sigma_{A}=\frac{P d}{4 t}
\end{gathered}
$$

The corresponding strains produced by the these stresses generated in the tubes are then worked out from the following relationships; 


$$
\begin{aligned}
& \varepsilon_{H}=\frac{\sigma_{H}}{E_{H}}-v_{A H} \frac{\sigma_{A}}{E_{A}} \\
& \varepsilon_{A}=\frac{\sigma_{A}}{E_{A}}-v_{H A} \frac{\sigma_{H}}{E_{H}}
\end{aligned}
$$

These strains were then transformed to the ply coordinate system by multiplying with the transformation matrix. Hence,

$$
\begin{aligned}
& \varepsilon_{1}=\varepsilon_{A} \cos ^{2} \theta+\varepsilon_{H} \sin ^{2} \theta \\
& \varepsilon_{2}=\varepsilon_{A} \sin ^{2} \theta+\varepsilon_{H} \cos ^{2} \theta \\
& \gamma_{12}=2 \sin \theta \cos \theta\left(\varepsilon_{H}-\varepsilon_{A}\right)
\end{aligned}
$$

Since the pipe wall is an angle ply laminate, the lamina can be considered to have orthotropic elastic properties, which are highly dependent on the winding angle $\theta$. Thus, the stress-strain response, at a low stress level where the stress strain behavior can be considered to be linear, and the stresses in the unidirectional ply can be written as follows;

$$
\left(\begin{array}{c}
\sigma_{1} \\
\sigma_{2} \\
\tau_{12}
\end{array}\right)=\left(\begin{array}{ccc}
Q_{11} & Q_{12} & 0 \\
Q_{12} & Q_{22} & 0 \\
0 & 0 & Q_{66}
\end{array}\right)\left(\begin{array}{c}
\varepsilon_{1} \\
\varepsilon_{1} \\
\gamma_{12}
\end{array}\right)
$$

where $Q_{11}, Q_{12}$ and etc. are the stiffness matrixes, which can be expressed in engineering terms as,

$$
\begin{array}{ll}
Q_{11}=\frac{E_{1}}{1-v_{12} v_{21}} ; & Q_{12}=\frac{v_{12} E_{1}}{1-v_{12} v_{21}}=\frac{v_{21} E_{2}}{1-v_{12} v_{21}} \\
Q_{22}=\frac{E_{2}}{1-v_{12} v_{21}} ; & Q_{66}=G_{12}
\end{array}
$$

where, $E_{1}$ and $E_{2}$ are the modulus of elasticity in the lamina's principal axes. However, due to the significant differences in the thermal expansions between the reinforcement materials and the matrix, it often causes the generation of residual stress prior to actual loading on the pipe. It is thus imperative that this generated thermal stress is taken into account when modeling the stress strain response.

\section{Non-Linear Response}

The previous section described the stress strain response of a GRE pipe at low strain level, which also took into account the effect of thermal stress. However, it is well known that at a higher strain level, obvious non-linearity existed. In this modeling work, the non-linearity prediction takes into account the effects of transverse matrix cracking during UEWS testing towards degradation of elastic properties of the pipes. The predictions are then plotted against the experimental strain data taken from the $10^{\text {th }}$ 
cycle of the UEWS tests of various hoops to the axial ratio. It is well discussed that the failure of GRE pipe is primarily controlled by the transverse matrix crack within the laminates, which occurs long before the final failure. The model developed here is used to predict the crack density of tubes as the function of applied stress, hence the subsequent non-linearity of the stress strain relationship caused by the initiation and progression of a matrix cracking under increasing pressure. From the finite element model, the deterioration in the transverse and shear modulus of composite laminates due to the increasing presence of matrix cracks can be estimated in the form of;

$$
\begin{aligned}
& \frac{E_{2}}{E_{2}^{o}}=\exp \left(-\alpha_{E 2} \rho^{*}\right) \\
& \frac{G_{2}}{G_{2}^{o}}=\exp \left(-\alpha_{G} \rho^{*}\right)
\end{aligned}
$$

where;

$E_{2}$ and $E_{2}{ }^{o}$ are the effective and initial transverse modulus of ply respectively, $G_{2}$ and $G_{2}{ }^{\circ}$ are the effective and initial shear modulus of ply respectively, $\alpha_{E 2}$ and $\alpha_{G}$ are the curve fitting constants $\rho$ is the normalized crack density function.

In this model, the non-linearity response as a result of matrix micro cracking only took place when the transverse stress in the ply reached the failure strength of the epoxy resin. Hence, the relationship between the crack density and applied stress can be derived (Roberts, Evans, Gibson, \& Frost, 2003) and given below;

$$
\rho=\kappa\left[\frac{\sigma_{2}-\sigma_{2}^{f a i l}}{\sigma_{2}^{\text {fail }}}\right]
$$

where; $\sigma_{2}$ is the limiting transverse stress in unidirectional ply

$$
\begin{aligned}
& \sigma_{2}^{\text {fail }} \text { is the failure strength of the matrix material } \\
& K=\sqrt{\frac{\left(E_{1}+E_{2}\right) G_{1}}{E_{1} E_{2}}} \text {, where } \mathrm{K} \text { involves only the ply modulus constants }
\end{aligned}
$$

The estimation of effective transverse and shear modulus of the ply at every pressure group increment can then be calculated from Equation (6). For close adaptation to the experimentally determined curve of all stress ratios, the curve fitting constants $\alpha_{E 2}$ and $\alpha_{G}$ were fitted by optimizing one constant at a time while retaining the value of the other. $\sigma_{2}^{\text {fail }}$, which is transverse failure stress, was adjusted and assigned to a constant value, thus demonstrating the effects of total stress on the laminate (Roberts et al., 2003). The effective modulus was then applied with laminate theory to determine the new corresponding axial and hoop modulus of the pipe after taking into account the effects of the matrix cracking. The gradually degraded stiffness calculated was later inserted into Equation (2) establishing the nonlinear stress strain response. 


\section{RESULTS AND DISCUSSION}

The laminate properties listed in Table 1, based on the ply properties of angle ply laminate lay up similar to the $\pm 55^{\circ}$ GRE pipe used in this investigation, were calculated using the laminate theory. However, the resin rich top coating of the pipes was often ignored as the structural element during calculation. The comparison between the mechanical properties obtained analytically and those by experimental means provided by FPI shows an acceptable agreement. This proves that the top coating of the outer surface of the pipe has a very minimal effect on the overall stiffness of the pipe. Even so, it is not able that these values are very much dependent on the volume fractions and their constituent properties. Thus, it must be determined experimentally prior to the UEWS tests and after weepage failure.

Table 1.Comparison between the mechanical properties of the GRE pipes provided for this investigation by Future Pipes Industries (FPI) and the calculated values.

\begin{tabular}{cccc}
\hline Property & $\begin{array}{c}\text { Value from } \\
\text { laminate theory }\end{array}$ & $\begin{array}{c}\text { Experimental value } \\
\text { by FPI }\end{array}$ & Difference (\%) \\
\hline Axial modulus, $E_{a x}$ & $11.52 \mathrm{GPa}$ & $11.5 \mathrm{GPa}$ & $0.2 \%$ \\
Hoop modulus, $E_{h p}$ & $19.70 \mathrm{GPa}$ & $19.0 \mathrm{GPa}$ & $3.7 \%$ \\
Poisson's ratio, $v_{a h}$ & 0.40 & 0.38 & $5.3 \%$ \\
Poisson's ratio, $v_{h a}$ & 0.69 & 0.65 & $6.2 \%$ \\
Shear modulus, $G_{a h}$ & $11.76 \mathrm{GPa}$ & $11.0 \mathrm{GPa}$ & $6.9 \%$ \\
\hline
\end{tabular}

\section{Stress-Strain Response of UEWS Tests}

The modeled stress strain curves for a different ratio of fitting constants $\alpha_{E 2} / \alpha_{G}$ at various ratios of UEWS tests are shown in Figure 2-5. The calculations are based on Equations 6-7 before being subjected to laminate theory to determine the corresponding strains in the pipe axes. Optimizations of the ratio of the fitting constant were carried out with the intention of getting the best possible match to the experimental strains of the $10^{\text {th }}$ cycle obtained from UEWS test with axial strains superimposed at different $\alpha_{E 2} / \alpha_{G}$ ratios. Throughout the modeling work, $\sigma_{2}^{\text {fail }}$ was chosen to be between $40-50 \mathrm{MPa}$, since these values give the best fit for all loading conditions.

At first, qualitative judgment on the results of the implemented model, suggests that they closely conform to the UEWS experimental data. In all loading conditions, the non-linearity modeled indicated slow change in the slope rather than abrupt change in response, which is normally seen and described as the knee point. Figure 2 shows the model curve fitting, together with the actual findings for UEWS test conducted at 2:1 hoop to the axial stress ratio, within the room temperature environment. As we can see from the plot, the ratio of curve fitting constants between $\alpha_{E 2}$ and $\alpha_{G}$ from Equation 6 can be seen increasing from 0.8 to 1.28 to give the best fit of the stress strain response with the experimental results. At the ratio of 0.8 , the stress strain behavior showed an almost linear response. At $\alpha_{E 2} / \alpha_{G}=1.0$, the curve in the non-linear section showed an upward shift to a higher strain value. A further increase of $\alpha_{E 2} / \alpha_{G}=1.28$, at the end gives good agreement on the non-linearity response to the experimental result for the case of 2:1 loading conditions. Here, it appears that by increasing the $\alpha_{E 2}$ constant, which relates the effects of matrix cracking to the deterioration in the transverse modulus, the 
model's curve can be matched very well to the non-linear behavior shown in the actual findings from UEWS tests.

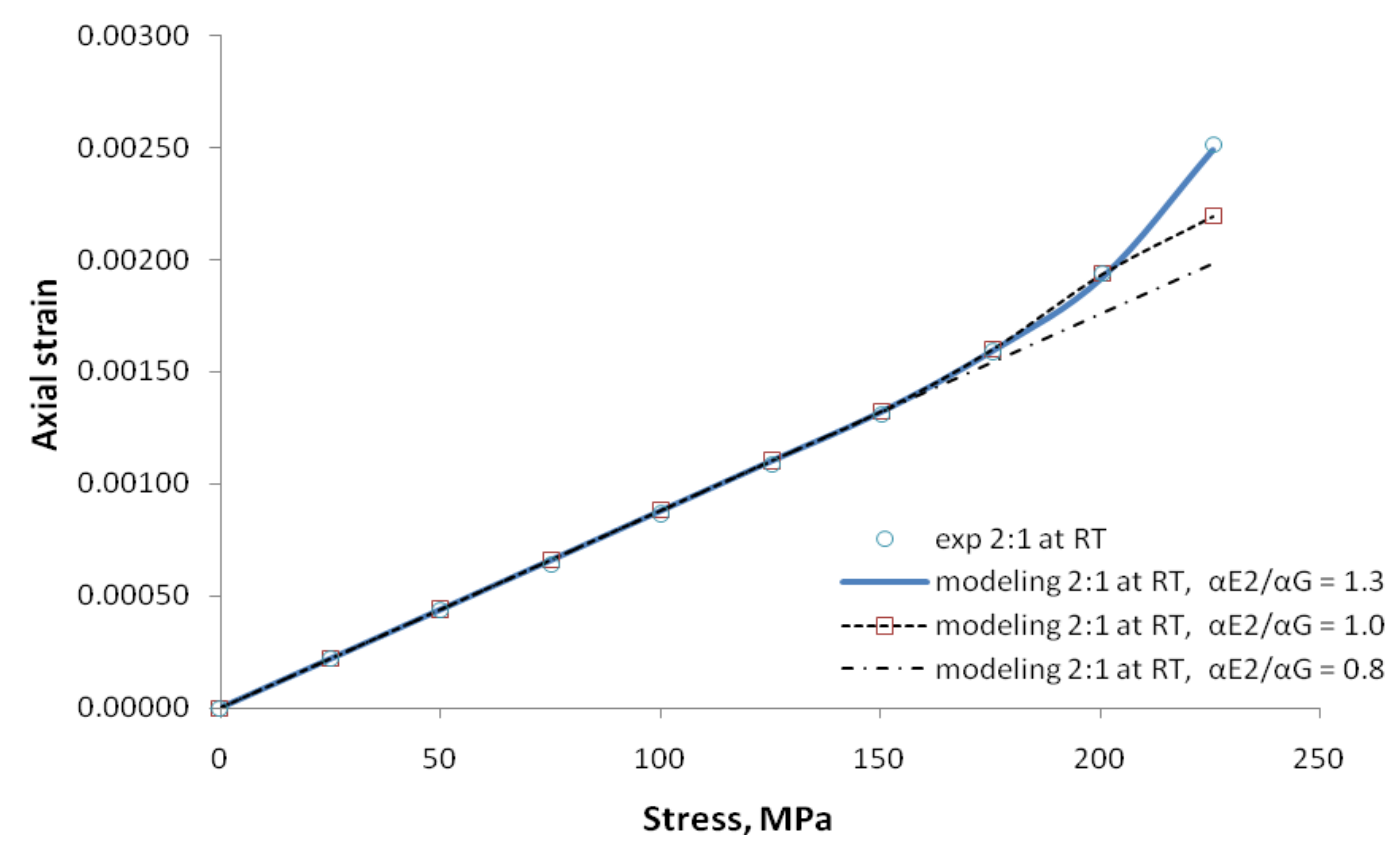

Figure 2. Experimental and model stress strain curve for UEWS test $(2: 1)$ at room temperature.

A similar trend was also noted for the cases of 1:1 loading and pure axial (0:1) loading conditions illustrated in Figures 3 and 4 respectively, although the modeled strains are slightly higher than those obtained experimentally, especially within the linear region. These slight discrepancies are probably due to the errors during testing or data scatters, which exist while analyzing the data. Considerable increased values of $\alpha_{E 2} / \alpha_{G}$ were attained for the case of these loadings. This implied that the non-linearity of the stress strain response during axial dominated loading has been largely caused by the deterioration in transverse modulus. For 1:1 loading, the best fit was obtained at $\alpha_{E 2} / \alpha_{G}=3.0$. Whilst pure axial loading, which presumably was more prone to transverse stiffness reduction by matrix cracking, showed the closest fit to experimental data at $\alpha_{E 2} / \alpha_{G}=6.0$, which is the highest of the previous two modeling results. This is because in this type of loading the load is very much dominated by the epoxy matrixes as reported by previous studies (Abdul Majid, 2011; Jones \& Hull, 1979; Khalifa, Zidi, \& Abdelwahed, 2012; Meijer \& Ellyin, 2008).

All in all, the failure strains for the three loading conditions were modeled closely to their experimental data, at $0.2 \%$ for $2: 1$ loading, whereas in $1: 1$ and pure axial loadings the failure strains were at $0.4 \%$ and $0.6 \%$ respectively. The change in the strains from linear to a non-linear responses in these loadings is due to the reduction in transverse stiffness as the crack density increases, leading to weepage failure. Contrary to previous results, for the pure hoop loading (1:0), the ratio between $\alpha_{E 2}$ and $\alpha_{G}$ showed a reduction from 1.0 to 0.625 to achieve the best fitting to experimental findings. As shown in Figure 5, at $\alpha_{E 2} / \alpha_{G}=1.0$, a practically linear stress strain behavior was established. Reducing the ratio of the fitting constant to 0.8 caused a downshift of the hoop strains indicating the start of the non-linear response, closer to the experimental 
results. Finally, optimization is achieved at $\alpha_{E 2} / \alpha_{G}=0.625$. This suggests that, unlike previous results, for hoop dominated loading the fitting constant $\alpha_{G}$ that relates to the deterioration of shear modulus, is more sensitive in causing the non-linear response outcome of the strains. UEWS points for this loading were taken at $\sigma_{H}=220 \mathrm{MPa}$, which later transformed to the ply stresses and resulted in $\tau_{12}=220 \mathrm{MPa}$.It is believed that that this stress was sufficient to cause shear failure in the resin system.

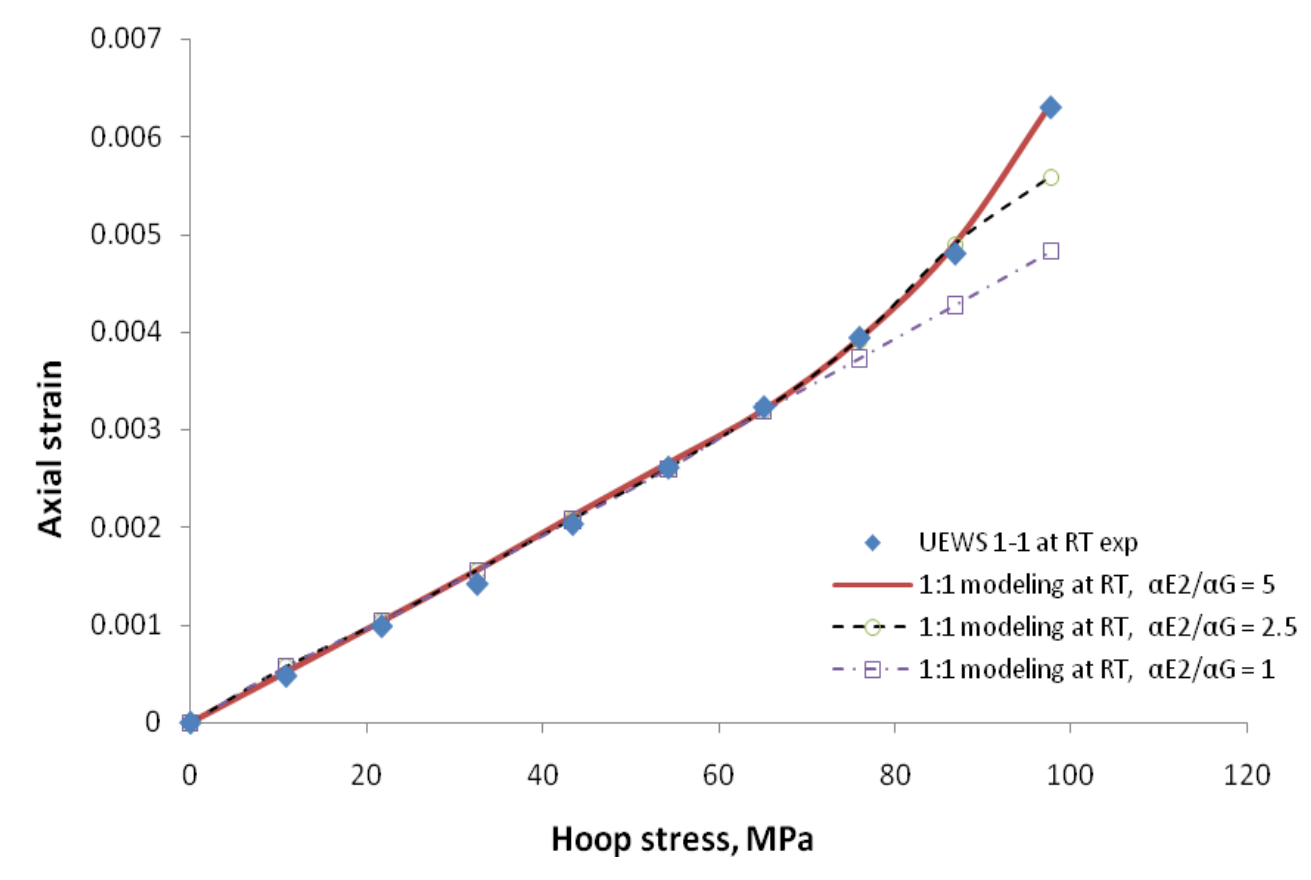

Figure 3. Experimental and model stress strain curve for UEWS test (1:1) at room temperature.

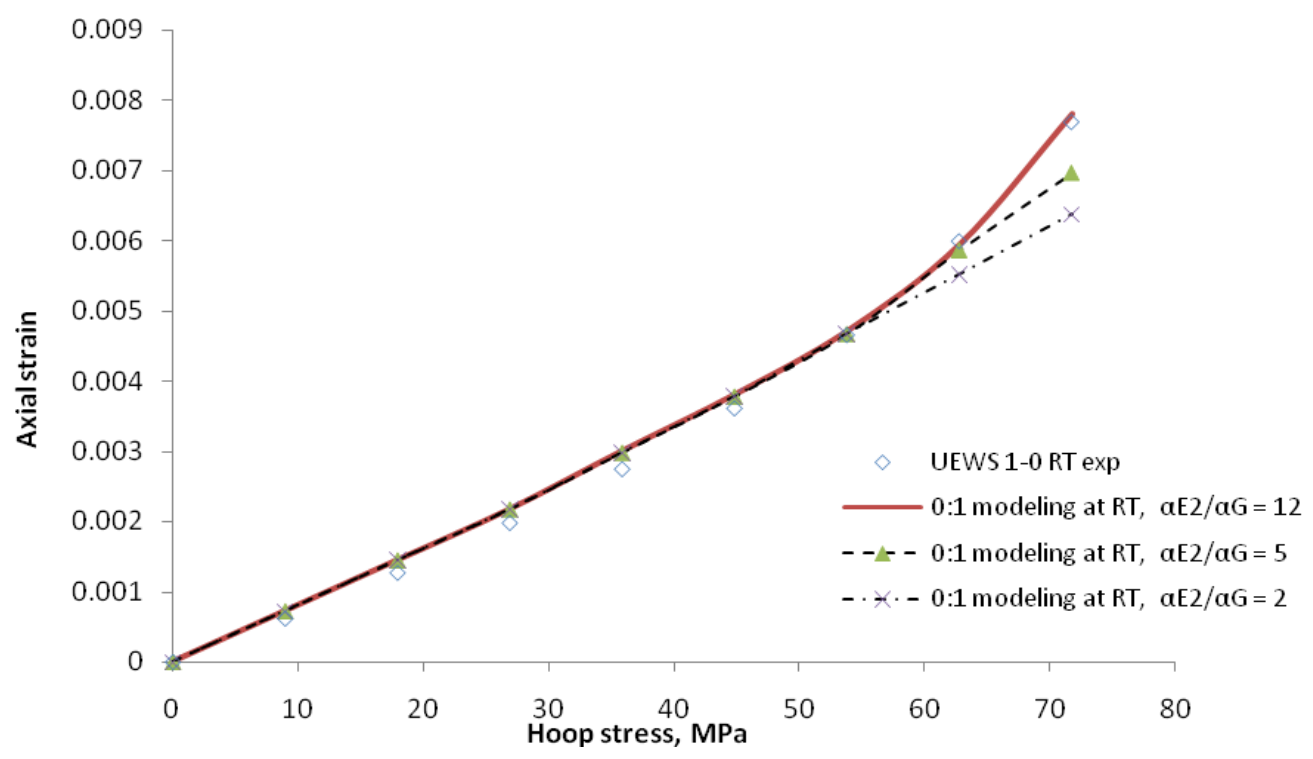

Figure 4. Experimental and model stress strain curve for UEWS test $(0: 1)$ at room temperature. 


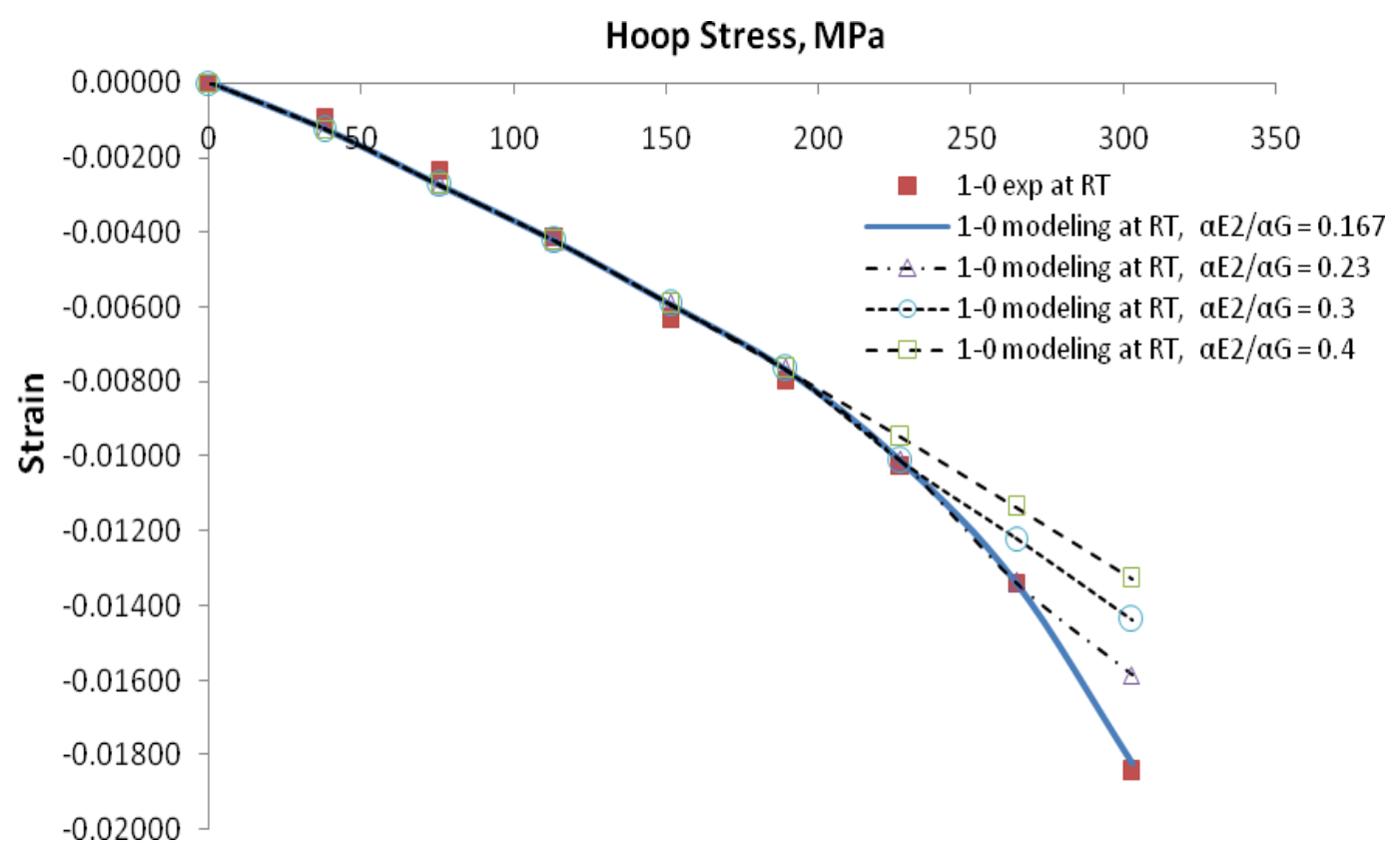

Figure 5. Experimental and model stress strain curve for UEWS test (1:0) at room temperature.

\section{CONCLUSIONS}

The stress-strain response as the result of increased transverse matrix cracking of GRE composite pipes under multiaxial UEWS tests is presented in this paper. The plots show that the model developed from the classical laminate theory, which takes into account the effects of transverse matrix micro-cracks on stiffness and strains, is capable of predicting the resulted elastic properties. The results from the model for all stress ratios showed good agreement with the experimental data. The ratio of curve fitting constants between $\alpha_{E 2}$ and $\alpha_{G}$, which relates the effects of matrix cracking to the deterioration in transverse modulus for hydrostatic loading (2:1) and axial dominated loadings (1:1 and $0: 1)$ were found to increase and noted to become more pronounced at axial dominated or pure axial loading $(0: 1)$. On the contrary, modeling for pure hoop loading (1:0) showed a reduction in the ratio between $\alpha_{E 2}$ and $\alpha_{G}$ from 1.0 to 0.625 to achieve the closest agreement to experimental data. This indicates that the fitting constant $\alpha_{G}$ which describes the degradation of shear modulus is more sensitive in causing the non-linear response outcome of the strains.

\section{ACKNOWLEDGEMENTS}

The work presented herein was supported by Future Pipes Industries, Netherlands, as part of a study of the performance of filament wound GRE pipes under grant RES/0590/7256. The authors would also like to acknowledge the financial support from the overseas postgraduate program of the Universiti Malaysia Perlis (UniMAP), Malaysia and Ministry of High Education (MOHE), Malaysia. 


\section{REFERENCES}

Abdul Majid, M. S., Assaleh, T.A., Gibson, A.G., Hale, J.M., Fahrer, A., Rookus, C.A.P., Hekman, M. (2011). Ultimate elastic wall stress (uews) test of glass fibre reinforced epoxy (gre) pipe. Composites Part A: Applied Science and Manufacturing, 42(10), 1500-1508.

Bachtiar, D., Sapuan, S. M., \& Hamdan, M. M. (2010). Flexural properties of alkaline treated sugar palm fibre reinforced epoxy composites. International Journal of Automotive and Mechanical Engineering, 1, 79-90.

Carvalho, A., \& Marques, C. (2007). A new formula to predict the structural life of composite pipes. JEC Composites Magazine, 44(33), 71-74.

Frost, S. R., \& Cervenka, A. (1994). Glass fibre-reinforced epoxy matrix filamentwound pipes for use in the oil industry. Composites Manufacturing, 5(2), 73-81.

Gibson, A. G., Abdul Majid, M. S., Assaleh, T. A., Hale, J. M., Fahrer, A., Rookus, C. A. P., \& Hekman, M. (2011). Qualification and lifetime modelling of fibreglass pipe. Plastics, Rubber and Composites, 40(2), 80-85.

Gibson, A. G., Saied, R. O., Evans, J. T., \& Hale, J. M. (2003a). Failure envelopes for glass fiber pipes in water up to 160c. Proceeding 'The 4th MERL International Conference, Oilfield Engineering with Polymer, 3-4 November, pp. 163-177, Institute of Electrical Engineers, London UK.

Gibson, A. G., Saied, R. O., Evans, J. T., \& Hale, J. M. (2003b). Failure envelopes for glass fiber pipes in water up to 160c. Paper presented at the Proceeding "The 4th MERL International Conference, Oilfield Engineering with Polymer, London UK.

Hale, J. M., Shaw, B. A., Speake, S. D., \& Gibson, A. G. (2000). High temperature failure envelopes for thermosetting composite pipes in water. Plastics, Rubber and Composites Processing and Applications, 29(10), 539-548.

Hanh, H. T., \& Tsai, S. W. (1974). On the behaviour of composite laminates after initial failures. Journal of Composite Materials, Vol. 8, 280-305.

Hashin, Z. (1985). Analysis of cracked laminates: A variational approach. Mechanics of Materials, 4(2), 121-136.

Highsmith, A. L., \& Reifsnider, K. L. (1982). Stiffness reduction mechanisms in composite laminates. . Damage in composite materials,, ASTM STP 775, 103117.

Hull, D., Legg, M. J., \& Spencer, B. (1978). Failure of glass/polyester filament wound pipe. Composites, 9(1), 17-24.

Jeffrey, K. J. T., Tarlochan, F., \& Rahman, M. M. (2011). Residual strength of chop strand mats glass fiber/epoxy composite structures: Effect of temperature and water absorption. International Journal of Automotive and Mechanical Engineering, 4, 504-519.

Jones, M. L. C., \& Hull, D. (1979). Microscopy of failure mechanisms in filamentwound pipe. Journal of Materials Science, 14(1), 165-174.

Kamal, M., Rahman, M. M., \& Rahman, A. G. A. (2012). Fatigue life evaluation of suspension knuckle using multibody simulation technique. Journal of Mechanical Engineering and Sciences, 3, 291-300.

Kamal, M., Rahman, M. M., \& Sani, M. S. M. (2013). Application of multibody simulation for fatigue life estimation. International Journal of Automotive and Mechanical Engineering, 7, 912-923. 
Katerelos, D. G., McCartney, L. N., \& Galiotis, C. (2006). Effect of off-axis matrix cracking on stiffness of symmetric angle-ply composite laminates. International journal of fracture, 139(3-4), 529-536.

Katerelos, D. T. G., Lundmark, P., Varna, J., \& Galiotis, C. (2007). Analysis of matrix cracking in gfrp laminates using raman spectroscopy. Composites Science and Technology, 67(9), 1946-1954.

Khalifa, A. B., Zidi, M., \& Abdelwahed, L. (2012). Mechanical characterization of glass/vinylester $\pm 55^{\circ}$ filament wound pipes by acoustic emission under axial monotonic loading. Comptes Rendus - Mecanique, 340(6), 453-460.

Laws, N., Dvorak, G. J., \& Hejazi, M. (1983). Stiffness changes in unidirectional composites caused by cracks systems. Mechanics of Materials, Vol. 2, 123-137.

Li, S., Reid, S. R., \& Soden, P. D. (1998). A continuum damage model for transverse matrix cracking in laminated fibre-reinforced composites. Philosophical Transactions of the Royal Society A: Mathematical, Physical and Engineering Sciences, 356(1746), 2379-2412.

Meijer, G., \& Ellyin, F. (2008). A failure envelope for $\pm 60^{\circ}$ filament wound glass fibre reinforced epoxy tubulars. Composites Part A: Applied Science and Manufacturing, 39(3), 555-564.

Mertiny, P., \& Ellyin, F. (2006). Performance of high-pressure fiber-reinforced polymer composite pipe structures. Paper presented at the American Society of Mechanical Engineers, Pressure Vessels and Piping Division (Publication) PVP.

Nairn, J. A., \& Hu, S. (1994). Matrix microcracking. In: Damage mechanics of composite materials. Talreja, r, editor. Amsterdam: Elsevier Science, Chapter 6, 187-243.

Norman, L., \& Dvorak, G. J. (1988). Progressive transverse cracking in composite laminates. Journal of Composite Materials, 22, 900-916.

Praveen, G. N., \& Reddy, J. N. (1998). Transverse matrix cracks in cross-ply laminates: Stress transfer, stiffness reduction and crack opening profiles. Acta mechanica, 130(3-4), 227-248.

Rahman, M. M., Ariffin, A. K., Rejab, M. R. M., Kadirgama, K., \& Noor, M. M. (2009). Multiaxial fatigue behavior of cylinder head for a free piston linear engine. Journal of Applied Sciences, 9(15), 2725-2734.

Ravi Sankar, H., Srikant, R. R., Vamsi Krishna, P., Bhujanga Rao, V., \& Bangaru Babu, P. (2013). Estimation of the dynamic properties of epoxy glass fabric composites with natural rubber particle inclusions. International Journal of Automotive and Mechanical Engineering, 7, 968-980.

Reifsnider, K. L., Henneke, E. G., Stinchcomb, W. W., \& Duke, J. C. (1983). Damage mechanics and nde of composite laminates, in mechanics of composite materials - recent advances. Pergamon Press, New York(399-420).

Roberts, S. J., Evans, J. T., Gibson, A. G., \& Frost, S. R. (2003). The effect of matrix microcracks on the stress-strain relationship in fiber composite tubes. Journal of Composite Materials, 37(17), 1509-1523.

Salleh, Z., Yusop, M. Y. M., \& Rosdi, M. S. (2013). Mechanical properties of activated carbon (ac) coir fibers reinforced with epoxy resin. Journal of Mechanical Engineering and Sciences, 5, 631-638.

Schwencke, H. F., De Ruyter van Stevenick, A.W. . (1968). The ultimate elastic wall stress (uews) of wavistrong pipes (a criterion for the determination of the working pressure of a grp pipe). 68-11(Shell Publication). 
Sun, C. T., \& Tao, J. (1998). Prediction of failure envelopes and stress/strain behaviour of composite laminates. Composites Science and Technology, 58(7), 1125-1136.

Tao, J. X., \& Sun, C. T. (1996). Effect of matrix cracking on stiffness of composite laminates. Mechanics of Composite Materials and Structures, 3(3), 225-239.

Tarakcioglu, N., Gemi, L., \& Yapici, A. (2005). Fatigue failure behavior of glass/epoxy \pm 55 filament wound pipes under internal pressure. Composites Science and Technology, 65(3-4), 703-708. 